Review

\title{
Tumor necrosis factor alpha is a promising circulating biomarker for the development of obstructive sleep apnea syndrome: a meta-analysis
}

\author{
Qingsheng $\mathbf{L i}^{1}$ and Xin Zheng ${ }^{2}$ \\ ${ }^{1}$ Department of Emergency Pediatrics, The First Affiliated Hospital of Fujian Medical University, Fuzhou, China \\ 2 Department of Basic Medicine, Fujian Health Collage, Fuzhou, China \\ Correspondence to: Xin Zheng, email: wysmhhm@sina.com \\ Keywords: obstructive sleep apnea syndrome; tumor necrosis factor alpha; meta-analysis; mean difference \\ Received: December 21, $2016 \quad$ Accepted: January 27, $2017 \quad$ Published: February 08, 2017 \\ Copyright: Li et al. This is an open-access article distributed under the terms of the Creative Commons Attribution License (CC-BY), which \\ permits unrestricted use, distribution, and reproduction in any medium, provided the original author and source are credited.
}

\section{ABSTRACT}

Obstructive sleep apnea syndrome (OSAS) is a chronic inflammatory disorder. The relationship between tumor necrosis factor alpha (TNF-alpha) and OSAS has been widely evaluated, but the results thus far remain inconclusive. We thereby decided to quantify the changes of TNF-alpha between OSAS patients and controls by a meta-analysis. This study complies with the MOOSE guidelines. Two reviewers independently searched articles and abstracted relevant data. In total, 47 articles (59 studies) were analyzed, including 2857 OSAS patients and 2115 controls. Overall, OSAS patients had a significantly higher level of circulating TNF-alpha than controls (weighted mean difference [WMD]: $9.66 \mathrm{pg} / \mathrm{mL}, 95 \%$ confidence interval [CI]: 8.66 to $11.24, P<0.001)$, but with significant heterogeneity $\left(I^{2}: 99.7 \%\right)$. After adjusting for potential missing studies, the overall estimate was weakened but still significant (filled WMD: $2.63 \mathrm{pg} / \mathrm{mL}, 95 \%$ CI: 2.56 to $2.70, P<0.001$ ). When studies were stratified by OSAS severity, the changes in circulating TNF-alpha between patients and controls increased gradually with the more severe grades of OSAS. In patients with mild, mild-to-moderate, moderate, moderate-to-severe and severe OSAS, circulating TNF-alpha was higher than respective controls by $0.99,1.48 .7 .79,10.08$ and 8.85 $\mathrm{pg} / \mathrm{mL}$, with significant heterogeneity $\left(I^{2}: 91.2 \%, 74.5 \%, 97.6 \%, 99.0 \%\right.$ and $\left.98.1 \%\right)$. In conclusion, our findings demonstrated that circulating TNF-alpha was significantly higher in OSAS patients than in controls, and this difference became more pronounced with the more severe grades of OSAS, indicating that TNF-alpha might be a promising circulating biomarker for the development of OSAS.

\section{INTRODUCTION}

Obstructive sleep apnea syndrome (OSAS) is a chronic inflammatory disorder featured by recurrent bouts of partial or complete upper airway obstruction during sleeping [1]. OSAS poses a major burden on individual and public health, as it respectively affects $10 \%$ and $17 \%$ of middle-aged (30-49 years old) and aged (50-70 years old) men, and $3 \%$ and $9 \%$ of middle-aged and aged women [2]. It is worth noting that affected individuals are more likely to suffer cardio- and cerebro-vascular diseases, such as hypertension, heart failure and stroke [3, 4]. At present, continuous positive airway pressure (CPAP) ranks as the main treatment option for patients with moderate or severe OSAS, and it can assist in reducing systematic inflammation in the airways of OSAS patients [5]. Hence, understanding the inflammation process may offer a possible clue to understanding the molecular mechanisms behind the pathogenesis of OSAS.

Several lines of evidence from animal experiments and clinical investigations have indicated that the presence of OSAS is associated with the increased production of inflammatory mediators [6,7]. Tumor necrosis factor alpha (TNF-alpha) is a key modulator of systematic inflammation [8-10], and TNF inhibition has proven to ameliorate the progression of OSAS [11]. Moreover, some researchers have observed a significant high level of circulating TNF-alpha in OSAS patients vis-à-vis healthy individuals [12-18], whereas others did not [19, 20]. The probable causes are multifaceted, relating to 
Table 1: The baseline characteristics of 59 studies in the present meta-analysis

\begin{tabular}{|c|c|c|c|c|c|c|c|c|c|c|c|c|c|c|c|c|c|c|c|c|}
\hline \multirow{2}{*}{ First author } & \multirow{2}{*}{ Year } & \multirow{2}{*}{ Country } & \multirow{2}{*}{$\begin{array}{l}\text { OSAS } \\
\text { severity }\end{array}$} & \multirow{2}{*}{ Type } & \multicolumn{2}{|c|}{ Sample size } & \multicolumn{2}{|c|}{ Age (years) } & \multicolumn{2}{|c|}{ Male gender } & \multicolumn{2}{|c|}{ BMI (kg/m2) } & \multicolumn{2}{|c|}{ Hypertension } & \multicolumn{2}{|c|}{ Diabetes } & \multicolumn{2}{|c|}{ AHI (events/h) } & \multicolumn{2}{|c|}{\begin{tabular}{|l} 
TNF-alpha \\
$\mathrm{mL})$
\end{tabular}} \\
\hline & & & & & Pati's & Cont's & Pati's & Cont's & Pati's & Cont's & Pati's & Cont's & Pati's & Cont's & Pati's & Cont's & Pati's & Cont's & Pati's & Cont's \\
\hline Vgontzas AN & 1997 & USA & All & C.S. & 12 & 10 & 40.9 & 24.1 & 0.92 & 1.00 & 40.5 & 24.6 & N.R. & N.R. & N.R. & N.R. & 63.7 & 0.0 & 2.51 & 1.17 \\
\hline Liu H & 2000 & China & All & C.S. & 22 & 16 & 47.4 & 47.6 & 0.68 & 0.69 & 27.6 & 23.1 & N.R. & N.R. & N.R. & N.R. & 44.0 & 4.3 & 299.09 & 101.88 \\
\hline Teramoto S & 2003 & Japan & All & C.S. & 40 & 40 & N.R. & N.R. & 0.85 & \begin{tabular}{|l|} 
N.R. \\
\end{tabular} & N.R. & N.R. & 0.00 & 0.00 & 0.00 & 0.00 & N.R. & N.R. & 9.50 & 4.40 \\
\hline Alberti A & 2003 & Italy & $\begin{array}{l}\text { Moderate- } \\
\text { to-severe }\end{array}$ & C.S. & 18 & 20 & 52.7 & 51.3 & 0.72 & 0.70 & 26.5 & 22.1 & 0.33 & 0.00 & 0.00 & 0.00 & $\mid 18.2$ & N.R. & 9.70 & 6.30 \\
\hline Minoguchi K (a) & 2004 & Japan & Mild & C.S. & 12 & 12 & 51.0 & 47.5 & 1.00 & 1.00 & 26.1 & 22.3 & 0.08 & 0.00 & 0.08 & 0.00 & 9.0 & 2.1 & 1.80 & 1.12 \\
\hline Minoguchi K (b) & 2004 & Japan & Moderate & C.S. & 12 & 12 & 49.2 & 47.5 & 1.00 & 1.00 & 29.1 & 22.3 & 0.25 & 0.00 & 0.08 & 0.00 & 59.2 & 2.1 & 2.34 & 1.12 \\
\hline Imagawa S & 2004 & Japan & Severe & C.S. & 110 & 45 & N.R. & N.R. & N.R. & N.R. & 28.5 & 22.9 & 0.00 & 0.00 & 0.00 & 0.00 & N.R. & N.R. & 28.60 & 25.00 \\
\hline Ciftci TU & 2004 & Turkey & All & C.S. & 43 & 22 & 49.6 & 47.2 & 1.00 & 1.00 & 31.9 & 31.0 & 0.00 & 0.00 & 0.00 & 0.00 & 33.2 & 1.6 & 4.60 & 3.29 \\
\hline Tam CS & 2006 & Australia & All & C.S. & 44 & 69 & 7.3 & 7.6 & 0.68 & 0.64 & 19.4 & 17.9 & 0.00 & 0.00 & 0.00 & 0.00 & N.R. & N.R. & 5.30 & 4.70 \\
\hline Ryan S (a) & 2006 & Ireland & $\begin{array}{l}\text { Mild-to- } \\
\text { moderate }\end{array}$ & N.S. & 35 & 30 & 42.0 & 41.0 & 1.00 & 1.00 & 32.9 & 30.7 & 0.00 & 0.00 & 0.00 & 0.00 & 15.9 & 1.2 & 4.15 & 3.21 \\
\hline Ryan S (b) & 2006 & Ireland & Severe & N.S. & 31 & 30 & 43.0 & 41.0 & 1.00 & 1.00 & 32.1 & 30.7 & 0.00 & 0.00 & 0.00 & 0.00 & 56.6 & 1.2 & 6.19 & 3.21 \\
\hline Kobayashi K & 2006 & Japan & Severe & C.S. & 35 & 16 & 51.4 & 41.0 & 0.86 & 0.81 & 27.9 & 27.4 & 0.49 & 0.44 & 0.20 & 0.19 & 52.3 & 9.0 & 1.11 & 0.62 \\
\hline Bravo Mde L & 2007 & Spain & $\begin{array}{l}\text { Moderate- } \\
\text { to-severe }\end{array}$ & C.S. & 50 & 20 & 52.3 & 47.4 & 1.00 & 1.00 & 30.9 & 28.4 & 0.68 & 0.00 & 0.00 & 0.00 & 48.9 & 2.5 & 0.89 & 0.42 \\
\hline $\operatorname{LiY}$ & 2008 & China & All & N.S. & 68 & 22 & 48.3 & 43.0 & 0.74 & 0.64 & 25.7 & 23.3 & 0.00 & 0.00 & 0.00 & 0.00 & 31.4 & 2.9 & 113.80 & 87.30 \\
\hline Li AM & 2008 & China & All & C.S. & 47 & 95 & 11.1 & 10.7 & 0.70 & 0.67 & N.R. & N.R. & N.R. & N.R. & N.R. & N.R. & 14.1 & 0.7 & 0.40 & 0.50 \\
\hline Kanbay A & 2008 & Turkey & All & C.S. & 106 & 32 & 51.4 & 44.8 & 0.58 & 0.59 & 31.1 & 28.3 & 0.47 & 0.38 & 0.24 & 0.17 & 40.1 & 2.0 & 114.15 & 34.25 \\
\hline Constantinidis J (a) & 2008 & Greece & All & C.S. & 13 & 12 & 45.1 & N.R. & 1.00 & 1.00 & 33.4 & 34.9 & N.R. & N.R. & N.R. & N.R. & 23.6 & 3.4 & 124.64 & 78.80 \\
\hline Constantinidis $\mathrm{J}$ (b) & 2008 & Greece & All & C.S. & 11 & 15 & 45.1 & N.R. & 1.00 & 1.00 & 26.1 & 27.4 & N.R. & N.R. & N.R. & N.R. & 22.9 & 3.6 & 105.00 & 48.50 \\
\hline Arias MA & 2008 & Spain & $\begin{array}{l}\text { Moderate- } \\
\text { to-severe }\end{array}$ & N.S. & 30 & 15 & 52.0 & 48.0 & 1.00 & 1.00 & 30.5 & 28.7 & 0.00 & 0.00 & 0.00 & 0.00 & 43.8 & 3.7 & 18.50 & 11.40 \\
\hline Antonopoulou S & 2008 & Greece & $\begin{array}{l}\text { Moderate- } \\
\text { to-severe }\end{array}$ & C.S. & 45 & 25 & 52.0 & 51.0 & 0.82 & 0.72 & 33.5 & 31.0 & 0.00 & 0.00 & 0.00 & 0.00 & 39.0 & N.R. & 1.40 & 0.64 \\
\hline Thomopoulos C & 2009 & Greece & All & C.S. & 62 & 70 & 48.1 & 48.1 & 0.79 & 0.80 & 31.9 & 32.1 & 1.00 & 1.00 & 0.00 & 0.00 & 31.6 & 0.4 & 2.14 & 1.26 \\
\hline Tamaki S (a) & 2009 & Japan & $\begin{array}{l}\text { Mild-to- } \\
\text { moderate }\end{array}$ & C.S. & 13 & 13 & 56.1 & 35.5 & 0.85 & 0.92 & 24.6 & 23.6 & 0.00 & 0.00 & 0.00 & 0.00 & 18.3 & 3.8 & 22.70 & 17.30 \\
\hline Tamaki S (b) & 2009 & Japan & Severe & C.S. & 20 & 13 & 50.5 & 35.5 & 0.95 & 0.92 & 30.7 & 23.6 & 0.00 & 0.00 & 0.00 & 0.00 & 60.4 & 3.8 & 30.20 & 17.30 \\
\hline $\operatorname{LiY}(a)$ & 2009 & China & Mild & C.S. & 22 & 22 & 48.0 & 43.0 & 0.68 & 0.64 & 25.7 & 23.3 & 0.00 & 0.00 & 0.00 & 0.00 & 14.1 & 2.9 & 102.30 & 87.30 \\
\hline $\operatorname{LiY}(b)$ & 2009 & China & Moderate & C.S. & 22 & 22 & 44.0 & 43.0 & 0.82 & 0.64 & 28.8 & 23.3 & 0.00 & 0.00 & 0.00 & 0.00 & 29.7 & 2.9 & 125.00 & 87.30 \\
\hline $\operatorname{LiY}(\mathrm{c})$ & 2009 & China & Severe & C.S. & 24 & 22 & 44.0 & 43.0 & 0.71 & 0.64 & 28.7 & 23.3 & 0.00 & 0.00 & 0.00 & 0.00 & 70.1 & 2.9 & 132.10 & 87.30 \\
\hline Carneiro G & 2009 & Brazil & All & C.S. & 16 & 13 & 40.1 & 38.8 & 1.00 & 1.00 & 46.9 & 42.8 & 0.54 & 0.69 & 0.00 & 0.00 & 65.7 & 3.2 & 10.70 & 7.50 \\
\hline Bhushan B & 2009 & India & $\begin{array}{l}\text { Moderate- } \\
\text { to-severe }\end{array}$ & C.S. & 104 & 103 & 46.2 & 44.0 & 0.81 & 0.63 & 31.5 & 30.9 & 0.00 & 0.00 & 0.00 & 0.00 & N.R. & N.R. & 113.04 & 76.23 \\
\hline Steiropoulos P & 2010 & Greece & Moderate & C.S. & 38 & 23 & 45.5 & 43.7 & 0.87 & 0.74 & 36.4 & 34.5 & 0.00 & 0.00 & 0.00 & 0.00 & 61.0 & 5.3 & 6.72 & 3.94 \\
\hline Sahlman J & 2010 & Finland & Mild & C.S. & 84 & 40 & 50.4 & 45.6 & 0.76 & 0.63 & 32.5 & 31.5 & 0.37 & 0.33 & 0.08 & 0.05 & 9.6 & 1.9 & 1.54 & 1.17 \\
\hline Li NF (a) & 2010 & China & $\begin{array}{l}\text { Moderate- } \\
\text { to-severe }\end{array}$ & C.S. & 113 & 97 & 45.5 & 44.2 & 0.75 & 0.76 & 27.8 & 26.9 & 0.00 & 0.00 & 0.00 & 0.00 & N.R. & N.R. & 19.98 & 13.10 \\
\hline Li NF (b) & 2010 & China & $\begin{array}{l}\text { Moderate- } \\
\text { to-severe }\end{array}$ & C.S. & 134 & 73 & 46.1 & 46.0 & 0.75 & 0.74 & 28.9 & 27.7 & 1.00 & 1.00 & 0.00 & 0.00 & N.R. & N.R. & 22.85 & 17.32 \\
\hline Kim J (a) & 2010 & Korea & Moderate & C.S. & 9 & 22 & 38.0 & 26.0 & N.R. & N.R. & 24.4 & 23.9 & 0.00 & 0.00 & 0.00 & 0.00 & 14.4 & 1.3 & 14.56 & 14.40 \\
\hline $\operatorname{Kim} J(b)$ & 2010 & Korea & Severe & C.S. & 28 & 22 & 42.0 & 26.0 & N.R. & N.R. & 28.7 & 23.9 & 0.00 & 0.00 & 0.00 & 0.00 & 52.7 & 1.3 & 15.32 & 14.40 \\
\hline Khalyfa A & 2011 & USA & All & C.S. & 60 & 80 & 7.2 & 7.2 & 0.50 & 0.50 & N.R. & N.R. & 0.00 & 0.00 & 0.00 & 0.00 & 8.9 & 0.5 & 459.80 & 295.60 \\
\hline Qian X & 2012 & China & Severe & C.S. & 30 & 40 & 45.0 & 46.3 & 1.00 & 1.00 & 29.4 & 24.1 & 0.00 & 0.00 & 0.03 & 0.03 & N.R. & N.R. & 115.00 & 114.00 \\
\hline Mederios CA (a) & 2012 & Brazil & $\begin{array}{l}\text { Mild-to- } \\
\text { moderate }\end{array}$ & C.S. & 15 & 15 & 62.6 & 62.5 & 0.73 & 0.40 & 24.5 & 25.8 & 0.73 & 0.40 & 0.13 & 0.07 & N.R. & N.R. & 0.84 & 0.32 \\
\hline Mederios CA (b) & 2012 & Brazil & Severe & C.S. & 35 & 15 & 65.0 & 62.5 & 0.57 & 0.40 & 25.9 & 25.8 & 0.86 & 0.40 & 0.26 & 0.07 & N.R. & N.R. & 2.09 & 0.32 \\
\hline
\end{tabular}




\begin{tabular}{|c|c|c|c|c|c|c|c|c|c|c|c|c|c|c|c|c|c|c|c|c|}
\hline Deboer MD & 2012 & USA & All & C.S. & 9 & 15 & 14.2 & 14.6 & 0.44 & 0.67 & N.R. & N.R. & 0.00 & 0.00 & 0.00 & 0.00 & 13.5 & 0.8 & 0.99 & 0.98 \\
\hline Fornadi K & 2012 & German & All & C.S. & 25 & 75 & 54.0 & 50.0 & 0.80 & 0.49 & 29.0 & 26.0 & N.R. & N.R. & N.R. & N.R. & N.R. & N.R. & 2.20 & 1.90 \\
\hline Yang D & 2013 & China & All & C.S. & 25 & 25 & 54.0 & 53.0 & 0.92 & 0.92 & 27.4 & 26.3 & 0.64 & N.R. & 0.20 & N.R. & 24.0 & 3.0 & 12.55 & 5.12 \\
\hline Hargens T & 2013 & USA & All & C.S. & 12 & 15 & 22.8 & 21.1 & 1.00 & 1.00 & 32.4 & 22.2 & 0.00 & 0.00 & 0.00 & 0.00 & 25.4 & 2.0 & 950 & 860 \\
\hline Driessen C & 2013 & Netherland & All & N.S. & 23 & 25 & 9.8 & 12.0 & 0.43 & 0.56 & 21.3 & 20.0 & N.R. & N.R. & N.R. & N.R. & 3.6 & 0.4 & 15.10 & 12.30 \\
\hline Doufas AG & 2013 & USA & All & C.S. & 33 & 15 & 34.0 & 31.0 & 1.00 & 1.00 & 26.0 & 24.0 & 0.00 & 0.00 & 0.00 & 0.00 & 13.0 & 2.4 & 7.88 & 7.77 \\
\hline Chen PC (a) & 2013 & China & Mild & C.S. & 23 & 20 & 40.0 & 42.0 & 0.74 & 0.75 & 27.5 & 26.0 & 0.00 & 0.00 & 0.00 & 0.00 & 8.6 & 3.3 & 2.80 & 1.20 \\
\hline Chen PC (b) & 2013 & China & Moderate & C.S. & 21 & 20 & 45.0 & 42.0 & 0.76 & 0.75 & 26.7 & 26.0 & 0.00 & 0.00 & 0.00 & 0.00 & 21.1 & 3.3 & 3.80 & 1.20 \\
\hline Alexopoulos EI (a) & 2013 & Greece & Mild & C.S. & 22 & 22 & 6.0 & 6.8 & 0.36 & 0.45 & N.R. & N.R. & 0.00 & 0.00 & 0.00 & 0.00 & 2.1 & 0.5 & 0.65 & 0.63 \\
\hline Alexopoulos EI (b) & 2013 & Greece & $\begin{array}{l}\text { Moderate- } \\
\text { to-severe }\end{array}$ & C.S. & 24 & 22 & 5.7 & 6.8 & 0.46 & 0.45 & N.R. & N.R. & 0.00 & 0.00 & 0.00 & 0.00 & 11.5 & 0.5 & 0.63 & 0.63 \\
\hline Yadav R & 2014 & UK & $\begin{array}{l}\text { Moderate- } \\
\text { to-severe }\end{array}$ & C.S. & 20 & 21 & 49.0 & 45.0 & 0.15 & 0.20 & 52.0 & 50.0 & 0.65 & 0.50 & 0.30 & 0.30 & 21.3 & 4.3 & 87.20 & 15.50 \\
\hline Nobili V & 2014 & Italy & All & N.S. & 39 & 26 & 11.8 & 11.6 & 0.56 & 0.62 & 28.3 & 26.4 & 0.13 & 0.19 & 0.03 & 0.04 & 4.4 & 0.5 & 2.20 & 6.80 \\
\hline Ciccone M (a) & 2014 & Italy & Mild & C.S. & 26 & 40 & 53.7 & 52.3 & 0.88 & 0.85 & 28.1 & 28.2 & 0.00 & 0.00 & 0.00 & 0.00 & 10.6 & 2.1 & 14.42 & 12.53 \\
\hline Ciccone M (b) & 2014 & Italy & $\begin{array}{l}\text { Moderate- } \\
\text { to-severe }\end{array}$ & C.S. & 54 & 40 & 52.3 & 52.3 & 0.83 & 0.85 & 28.8 & 28.2 & 0.00 & 0.00 & 0.00 & 0.00 & 45.1 & 2.1 & 22.83 & 12.53 \\
\hline Zhang Y & 2015 & China & $\begin{array}{l}\text { Moderate- } \\
\text { to-severe }\end{array}$ & C.S. & 408 & 394 & 48.5 & 48.8 & 0.84 & 0.82 & 28.8 & 23.5 & 0.00 & 0.00 & 0.00 & 0.00 & N.R. & N.R. & 64.72 & 30.56 \\
\hline Thunstrom E & 2015 & Sweden & $\begin{array}{l}\text { Moderate- } \\
\text { to-severe }\end{array}$ & N.S. & 234 & 95 & 65.3 & 61.4 & 0.87 & 0.75 & 26.8 & 25.2 & 0.59 & 0.45 & 0.15 & 0.13 & 28.9 & 3.1 & 5.00 & 4.20 \\
\hline Leon-Cabrera S & 2015 & Mexico & $\begin{array}{l}\text { Moderate- } \\
\text { to-severe }\end{array}$ & C.S. & 29 & 10 & 37.2 & 43.4 & 0.14 & 0.80 & 45.2 & 23.6 & 0.00 & 0.00 & 0.00 & 0.00 & 51.4 & 7.5 & 337.90 & 270.20 \\
\hline Jiang $\mathrm{H}$ & 2015 & China & All & C.S. & 135 & 94 & 48.7 & 47.2 & 0.59 & 0.59 & 27.5 & 27.5 & 0.00 & 0.00 & 0.00 & 0.00 & 24.6 & 1.6 & 765.77 & 232.24 \\
\hline De Santis S & 2015 & Italy & All & C.S. & 26 & 24 & 41.8 & 43.7 & 0.65 & 0.67 & 33.0 & 30.8 & 0.00 & 0.00 & 0.00 & 0.00 & 26.2 & 1.7 & 122.20 & 80.20 \\
\hline Lin CC & 2016 & China & All & N.S. & 35 & 20 & 46.0 & 43.0 & 0.86 & 0.90 & 29.2 & 28.2 & 0.00 & 0.00 & 0.00 & 0.00 & 59.3 & 3.6 & 25.00 & 14.00 \\
\hline Ifergane $\mathrm{G}$ & 2016 & Israel & $\begin{array}{l}\text { Moderate- } \\
\text { to-severe }\end{array}$ & C.S. & 21 & 22 & 66.0 & 66.1 & 0.38 & 0.23 & 29.6 & 26.8 & 0.76 & 0.59 & 0.24 & 0.27 & N.R. & N.R. & 6.39 & 3.57 \\
\hline
\end{tabular}

Abbreviations: Pati's, patients; Cont's, controls; C.S., cross-sectional case-control study; N.S., nested case-control study; BMI, body mass index; AHI, apnea-hypopnea index; TNF-alpha, tumor necrosis factor alpha; N.R., data not reported.

statistical power, research design, genetic heterogeneity or dietary habit. The inconsistent reported relations and many resulting debates motivated us to postulate that circulating TNF-alpha might be a promising intermediate biomarker for predicting OSAS development. To uphold this postulation, we conducted an extensive search of current literature for published articles that reported data on circulating TNF-alpha between OSAS patients and controls, and thereby quantified the changes of TNF-alpha by a meta-analysis.

\section{RESULTS}

After searching three public databases, a total of 171 articles written in English language were indexed. After reviewing the title and abstract of each article, 99 were excluded for definitive reasons. After reading the full text of the rest 72 potential articles, 25 were further excluded, leaving 47 qualified articles in this metaanalysis according to the preset inclusive criteria [1258]. Because 9 articles provided data by OSAS severity, 1 article by hypertension and 1 article by obesity, there were a total of 59 independent studies involving 2857 OSAS patients and 2115 controls in the final analysis. The baseline characteristics of 59 studies are summarized in Table 1 and Supplementray Table 1.

Of 59 qualified studies, 25 were from Asian countries, 21 from European countries, 5 from North American countries, 3 from South American countries, 3 from cross-continent countries, 1 respectively from Australia and Latin America. 13 studies involved only male individuals, and 7 studies involved underage individuals. Age was reportedly matched between patients and controls by 23 studies, and there were 35 studies involving individuals free of hypertension and diabetes mellitus. There were 51 and 8 cross-sectional and nested case-control studies, respectively. OSAS was diagnosed by polysomnography by 51 studies. As for OSAS severity, mild OSAS was reported by 6 studies, mild-to-moderate OSAS by 3 studies, moderate OSAS by 5 studies, moderate-to-severe OSAS by 14 studies and severe OSAS by 8 studies.

When 59 qualified studies were pooled together, OSAS patients were observed to have a significantly higher level of circulating TNF-alpha than controls (WMD: $9.66 \mathrm{pg} / \mathrm{mL}, 95 \%$ CI: 8.66 to $11.24, P<0.001$ ) (Figure 1). Attention must be paid to this significant overall estimate, as heterogeneity across studies reached 
as high as $99.7 \%$ and the probability of Egger's test was 0.012 . The filled funnel plot indicated that there were 11 missing studies with negative findings (Figure 2), and after adjusting for these missing studies, overall estimate was weakened but still significant (filled WMD: $2.63 \mathrm{pg} / \mathrm{mL}$, 95\% CI: 2.56 to $2.70, P<0.001)$.

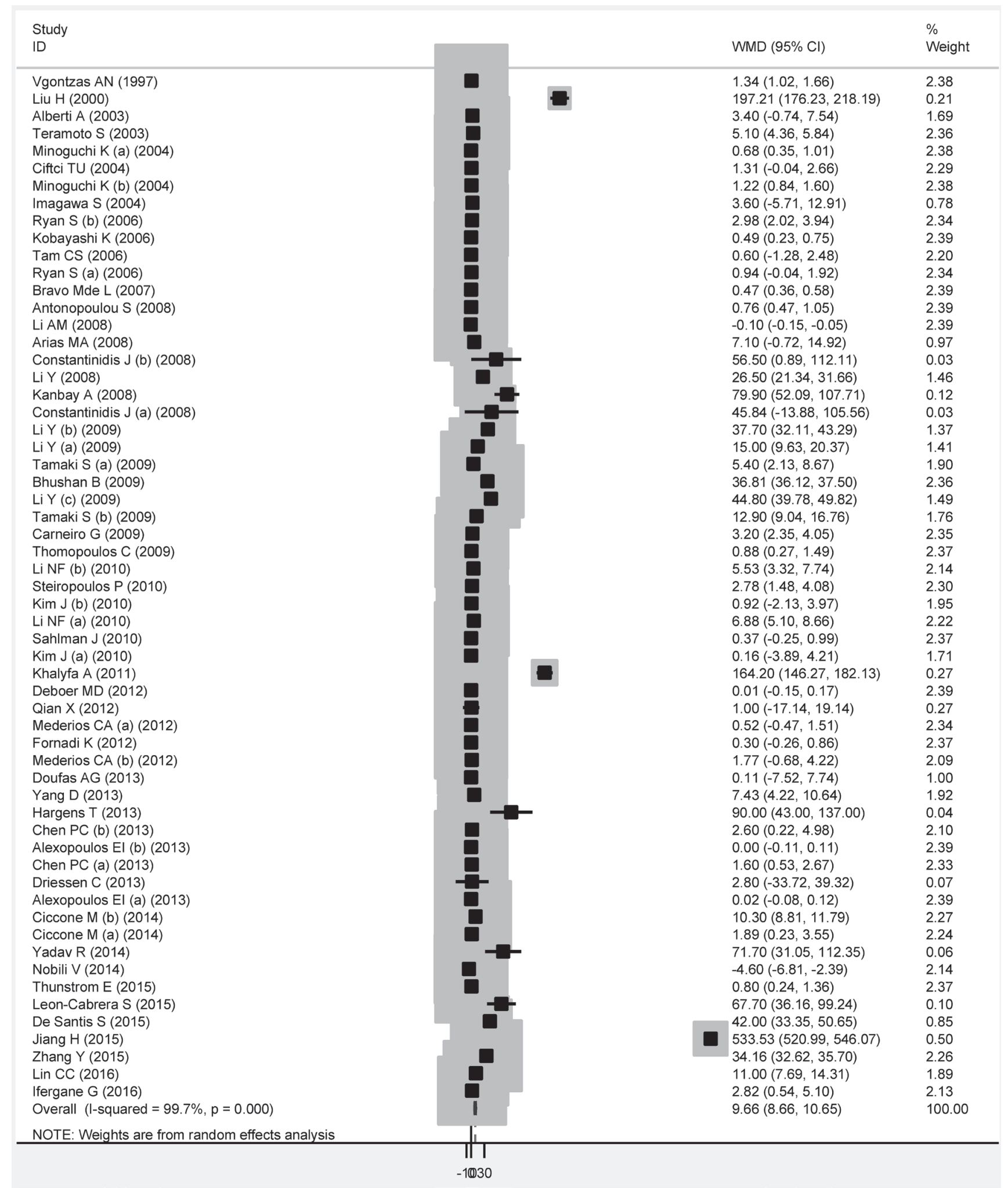

Figure 1: The forest plot for circulating TNF-alpha changes between OSAS patients and controls. Abbreviations: WMD, weighted mean difference; $95 \%$ CI, 95\% confidence interval; $I$-squared, inconsistency index. The x-axis represents the changes of circulating TNF-alpha between patients and controls in $\mathrm{pg} / \mathrm{mL}$. 


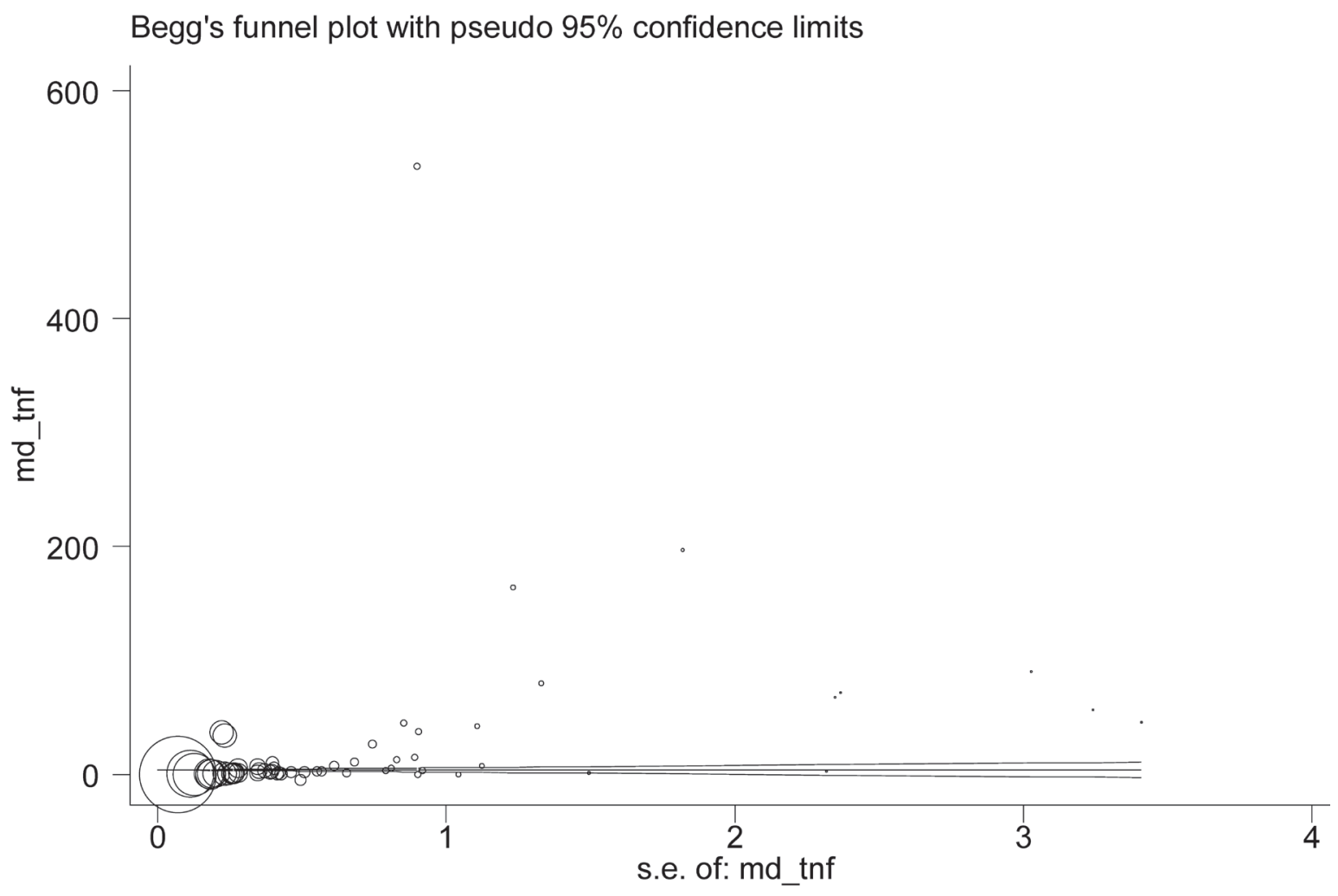

Filled funnel plot with pseudo $95 \%$ confidence limits

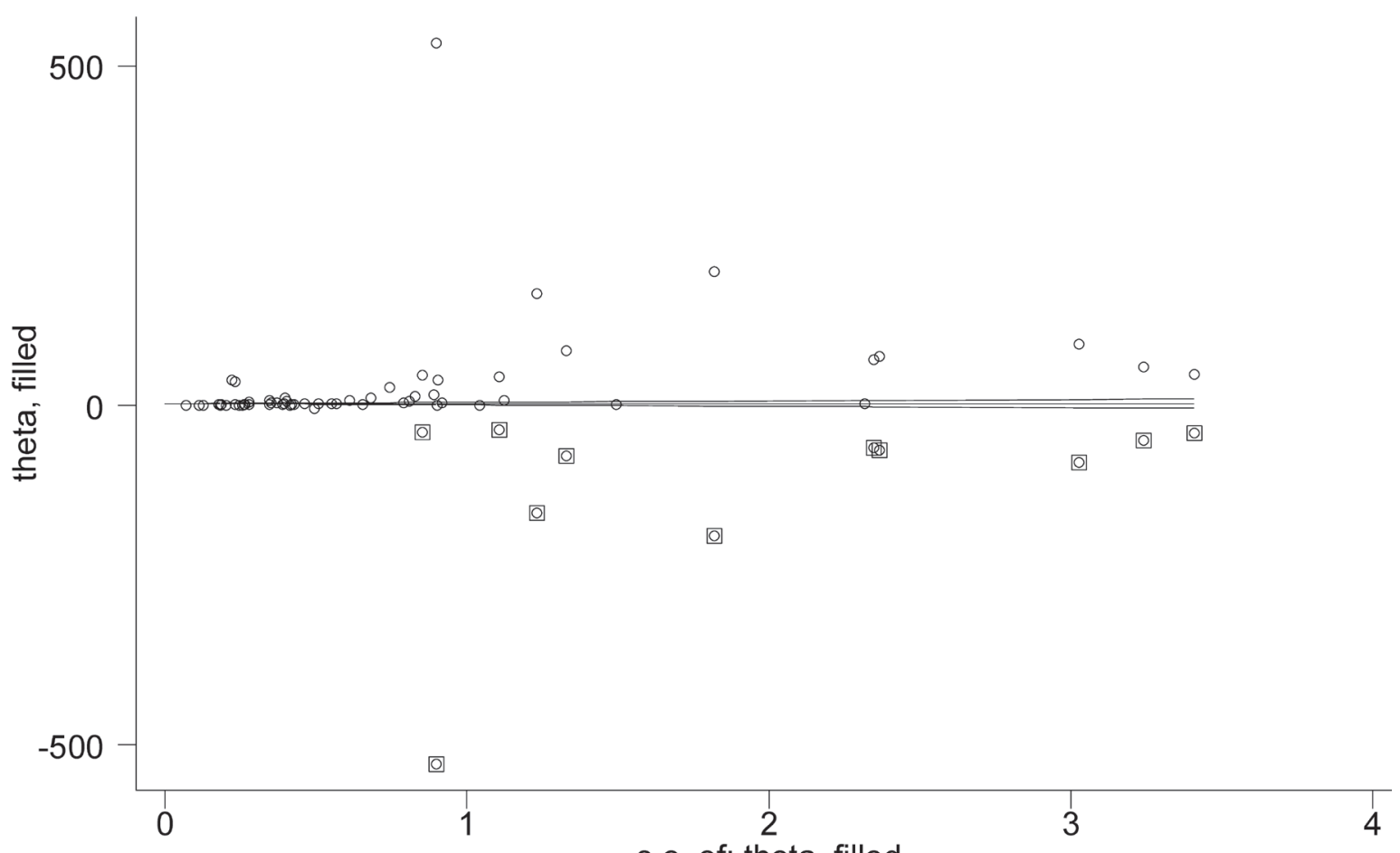

s.e. of: theta, filled

Figure 2: The Begg's (the upper) and filled (the lower) funnel plots for circulating TNF-alpha changes between OSAS patients and controls. In the upper plot, the "md_tnf" in the y-axis is the mean difference of circulating TNF-alpha in $\mathrm{pg} / \mathrm{mL}$, and the "s.e. of: md_tnf" in the $\mathrm{x}$-axis is the standard error of mean difference in circulating TNF-alpha. In the lower plot, the "theta" is the mean difference of circulating TNF-alpha in $\mathrm{pg} / \mathrm{mL}$, and the "s.e. of: theta" is the standard error of mean difference in circulating TNF-alpha. 
Table 2: Stratified analyses on circulating TNF-alpha changes between OSAS patients and controls

\begin{tabular}{|c|c|c|c|c|c|c|}
\hline \multicolumn{2}{|c|}{ Subgroups } & \multirow{2}{*}{$\frac{\text { No. of studies }}{13}$} & \multirow{2}{*}{$\frac{\text { WMD }}{1.52}$} & \multirow{2}{*}{$\frac{\mathbf{9 5 \%} \mathbf{C I}}{0.87 \text { to } 2.18}$} & \multirow{2}{*}{$\frac{\boldsymbol{P}}{<0.001}$} & \multirow{2}{*}{$\frac{\boldsymbol{I}^{2}}{87.9 \%}$} \\
\hline Gender & Male & & & & & \\
\hline Age & Underage & 7 & 0.00 & -0.813 to 0.804 & 0.991 & $99.8 \%$ \\
\hline Complication & Without Hypertension-DM & 35 & 17.46 & 15.70 to 19.21 & $<0.001$ & $99.8 \%$ \\
\hline Match & Matched by age & 23 & 28.57 & 24.01 to 33.12 & $<0.001$ & $99.9 \%$ \\
\hline Diagnosis & Polysomnography & 51 & 10.35 & 9.29 to 11.41 & $<0.001$ & $99.8 \%$ \\
\hline \multirow[t]{6}{*}{ Country } & Brazil & 3 & 1.85 & -0.17 to 3.87 & 0.073 & $87.7 \%$ \\
\hline & China & 15 & 58.59 & 46.45 to 70.73 & $<0.001$ & $99.9 \%$ \\
\hline & Greece & 7 & 0.48 & 0.13 to 0.83 & 0.007 & $88.9 \%$ \\
\hline & Italy & 5 & 9.32 & 1.71 to 16.93 & 0.016 & $98.0 \%$ \\
\hline & Japan & 7 & 2.99 & 1.70 to 4.29 & $<0.001$ & $96.7 \%$ \\
\hline & USA & 5 & 6.00 & 2.75 to 9.24 & $<0.001$ & $99.0 \%$ \\
\hline \multirow[t]{2}{*}{ Development } & Developed countries & 27 & 2.37 & 1.69 to 3.05 & $<0.001$ & $97.2 \%$ \\
\hline & Developing countries & 32 & 17.17 & 15.47 to 18.87 & $<0.001$ & $99.9 \%$ \\
\hline \multirow[t]{5}{*}{ Continent } & Asian & 25 & 29.84 & 26.21 to 33.47 & $<0.001$ & $99.9 \%$ \\
\hline & European & 21 & 1.28 & 0.84 to 1.71 & $<0.001$ & $95.4 \%$ \\
\hline & North American & 5 & 6.00 & 2.75 to 9.24 & $<0.001$ & $99.0 \%$ \\
\hline & South American & 3 & 1.85 & -0.17 to 3.87 & 0.073 & $99.7 \%$ \\
\hline & Cross-continent & 3 & 6.50 & -0.58 to 13.58 & 0.072 & $93.7 \%$ \\
\hline \multirow[t]{6}{*}{ OSAS severity } & All & 23 & 22.48 & 20.11 to 24.84 & $<0.001$ & $99.7 \%$ \\
\hline & Mild & 6 & 0.99 & 0.25 to 1.73 & 0.009 & $91.2 \%$ \\
\hline & Mild-to-oderate & 3 & 1.48 & -0.11 to 3.06 & 0.068 & $74.5 \%$ \\
\hline & Moderate & 5 & 7.79 & 3.01 to 12.57 & 0.001 & $97.6 \%$ \\
\hline & Moderate-to-severe & 14 & 10.08 & 6.92 to 13.25 & $<0.001$ & $99.9 \%$ \\
\hline & Severe & 8 & 8.85 & 4.40 to 13.31 & $<0.001$ & $98.1 \%$ \\
\hline \multirow[t]{2}{*}{ Research type } & Nested design & 8 & 5.10 & 2.25 to 7.95 & $<0.001$ & $95.9 \%$ \\
\hline & Cross-sectional design & 51 & 10.41 & 9.34 to 11.49 & $<0.001$ & $99.7 \%$ \\
\hline
\end{tabular}

Abbreviations: WMD, weighted mean difference; $95 \%$ CI, 95\% confidence interval; $I^{2}$, inconsistency index.

Stratified analyses according to age, gender, country, hypertension, diabetes mellitus, research type, matched condition, diagnostic criteria of controls, diagnostic criteria of OSAS and OSAS grade are shown in Table 2. In the analysis of studies involving underage individuals, there was no significant difference in circulating TNFalpha between OSAS patients and controls (WMD: $0.00 \mathrm{pg} / \mathrm{mL}, 95 \% \mathrm{CI}:-0.81$ to $0.80, P=0.991)$. After restricting analysis to males only, circulating TNF-alpha was significantly higher in OSAS patients than in controls (WMD: $1.52 \mathrm{pg} / \mathrm{mL}, 95 \% \mathrm{CI}: 0.87$ to $2.18, P<0.001$ ). This change was markedly reinforced in individuals free of hypertension and diabetes mellitus (WMD: $17.46 \mathrm{pg} /$ $\mathrm{mL}, 95 \%$ CI: 15.70 to $19.21, P<0.001)$, in studies with age-matched patients and controls (WMD: $28.57 \mathrm{pg} / \mathrm{mL}$,
$95 \%$ CI: 24.01 to $33.12, P<0.001)$ and in studies adopting polysomnography to diagnose OSAS (WMD: $10.35 \mathrm{pg} /$ $\mathrm{mL}, 95 \% \mathrm{CI}: 9.29$ to $11.41, P<0.001)$.

In the following stratified analyses, only subgroups involving 3 or more studies were displayed. By country, OSAS patients vis-à-vis controls had remarkably high circulating TNF-alpha in China (WMD: $58.59 \mathrm{pg} / \mathrm{mL}$, $P<0.001)$. When grouping studies by development, the changes in circulating TNF-alpha were strongly potentiated in developing countries (WMD: $17.17 \mathrm{pg} / \mathrm{mL}$ ) than in developed countries (WMD: $2.37 \mathrm{pg} / \mathrm{mL}$ ). Further by continent, the change was the highest in Asia (WMD: $29.84 \mathrm{pg} / \mathrm{mL}$ ), followed by North America (WMD: 6.00 $\mathrm{pg} / \mathrm{mL}$ ) and Europe (WMD: $1.28 \mathrm{pg} / \mathrm{mL}$ ). By research type, this change in cross-sectional case-control studies 
(WMD: $10.41 \mathrm{pg} / \mathrm{mL}$ ) was overwhelming relative to nested case-control studies (WMD: $5.10 \mathrm{pg} / \mathrm{mL}$ ). When studies were stratified by OSAS severity, the changes in circulating TNF-alpha between patients and controls increased gradually with the more severe grades of OSAS. In patients with mild, mild-to-moderate, moderate, moderate-to-severe and severe OSAS, circulating TNFalpha was higher than respective controls by 0.99 , 1.48. $7.79,10.08$ and $8.85 \mathrm{pg} / \mathrm{mL}$. In spite of the above stratified analyses, there was no immediate improvement in between-study heterogeneity.

A meta-regression analysis was hence conducted to see the impact of other confounding factors on the changes of circulating TNF-alpha between OSAS patients and controls. After regressing all possible confounders as mentioned in the Methods, only abdomen circumference and IL-6 were found to exert a significant impact on the changes of circulating TNF-alpha (abdomen circumference: $P<0.001$ in patients and $P=0.026$ in controls; IL-6: $P=0.001$ in patients and $P=0.003$ in controls). No significance was found for the other confounders (data not shown). In view of this significant finding, correlation analysis was conducted to test the relationship of circulating TNF-alpha with abdomen circumference and IL-6. The correlation of circulating TNF-alpha with abdomen circumference was marginal $(P$ $=0.078)$, while the correlation with IL-6 was remarkably significant $(P<0.001)$.

\section{DISCUSSION}

On the basis of 59 studies and 4972 individuals, this meta-analysis aimed to quantify the changes of circulating TNF-alpha between OSAS patients and controls. Our results illustrated that circulating TNF-alpha was significantly higher in OSAS patients than in controls, and this difference became more pronounced with the more severe grades of OSAS, indicating that TNF-alpha might be a promising circulating biomarker for the development of OSAS.

There is strong evidence that TNF-alpha is a central regulator of inflammation, and its antagonists have proven to be efficacious in treating inflammatory diseases [59, 60]. OSAS is a chronic inflammatory disorder, and its presence can lead to the increased production of some inflammatory mediators in circulation, including TNFalpha. An animal study found that the excessive sleepiness incurred by recurrent arousals during sleep might be due to the activation of TNF-alpha-depended inflammatory pathways [61, 62]. In addition, expression data showed that TNF-alpha was highly expressed in the heaviest OSAS patients relative to the less obese OSAS patients and non-apneic snorers [63]. The association of circulating TNF-alpha with OSAS risk has been widely evaluated, while no consensus exists in up-to-date literature [19, 51-54]. Based on these observations, it is reasonable to postulate that circulating TNF-alpha might be a clinical useful indicator for predicting OSAS risk. To shed some light on this postulation, we comprehensively analyzed the results of 59 studies through a meta-analysis and aimed to derive a reliable estimate between circulating TNF-alpha and OSAS.

A previous meta-analysis of 19 studies by Nadeem et al demonstrated that OSAS patients had higher circulating TNF-alpha than controls by $1.03 \mathrm{pg} / \mathrm{mL}$, and this difference was confused by obvious heterogeneity that remained unexplored in their study [64]. The present metaanalysis by pooling the results of 59 studies confirmed and strengthened this significant difference by deriving an unbiased estimate of $2.63 \mathrm{pg} / \mathrm{mL}$ for circulating TNFalpha in the trim-and-fill analysis. As with a majority of meta-analyses, we should be circumspect about the impact of between-study heterogeneity, as not every study's methodological and clinical aspects are identical [65]. In light of the differences in OSAS severity, research type, matched condition and so forth in the present metaanalysis, we can at least expound on some degree of heterogeneity, which accounted for part of conflicting findings in the literature. As it turns out, our stratified analyses demonstrated that the country, research type and OSAS severity might be possible sources of heterogeneity. It is worth mentioning that with the more severe grades of OSAS defined by AHI, circulating TNF-alpha was much higher in patients than in controls. Although the observational nature of all involved studies in this meta-analysis precluded the causal-effect exploration between circulating TNF-alpha and OSAS, our findings may provide indirect evidence that TNF-alpha might be a promising circulating biomarker for the development of OSAS. We concede that whether elevated circulating TNF-alpha is the cause or the effect of OSAS remains an open question. In the future, clinical trials are warranted to dissect this relation.

In spite of clear strengths including a large number of qualified studies and a comprehensive exploration on heterogeneity, it should be realized that there are several limitations to association studies included in this metaanalysis. First, selection bias might be possible given that only English articles were indexed. Although there was a significant probability of publication bias, the filled effect estimate after adjusting for missing studies was still significant in circulating TNF-alpha between OSAS patients and controls. Second, the results of this meta-analysis were based on 59 studies, while the total sample was not large enough. The power to reject the null hypothesis is very limited in some subgroup analyses. Third, between-study heterogeneity cannot be fully accounted for, in spite of a wide panel of stratified analyses conducted. It will be encouraging to explore the other sources of methodological and clinical aspects to mitigate heterogeneity. Moreover, this meta-analysis was undertaken with summary data, and to thoroughly 
account for heterogeneity one usually needs to perform a meta-analysis based on individual participant data, which are not always feasible. Fourth, the impact of obesity on the relationship between circulating TNF-alpha and OSAS cannot be solved due to the lack of necessary data, although it is increasingly recognized that obesity is an established risk factor for OSAS.

In sum, this meta-analysis of 59 studies and 4972 individuals demonstrated that circulating TNF-alpha was significantly higher in OSAS patients than in controls, and this difference became more pronounced with the more severe grades of OSAS, indicating that TNF-alpha might be a promising circulating biomarker for the development of OSAS. Our results, as are of consequence, deserve to be tested through relevant biological means and validated in large, well-designed prospective studies.

\section{MATERIALS AND METHODS}

This is a systematic meta-analysis on observational data, and its conduct complies with the guidelines enacted by the Meta-analysis Of Observational Studies in Epidemiology (MOOSE) group [66].

Using public databases of PubMed, Embase and Web of Science, articles that reported the changes of circulating TNF-alpha between OSAS patients and controls were indexed on November 3, 2016. Research content was confined to materials written in English language only. Included articles had to meet the following criteria: (i) OSAS as the clinical endpoint diagnosed by standard methods; (ii) case-control study design; (iii) availability of serum or plasma TNF-alpha levels expressed as mean or median value along with standard deviation or standard error or $95 \%$ confidence interval (95\% CI) or interquartile range or range in both OSAS patients and controls.

Exclusion process of candidate articles was accomplished with two steps: first, the title and abstract were reviewed to remove articles that were clearly irrelevant, such as animal experiments or clinical interventions; second, the full text of the remaining articles was evaluated according to the inclusive criteria, and meanwhile the reference list of each qualified article was also inspected to avoid possible loss of candidates. Two reviewers (Qingsheng Li and Xin Zheng) independently implemented literature search and exclusion process, and they settled all inconsistencies by discussion.

The following data were drawn from each qualified article: the first author's surname, publication year, country where study samples were collected from, research type, diagnostic criteria and method of OSAS, sample size, matched condition, age, gender, body mass index (BMI), abdomen circumference, neck circumference, smoking, hypertension, diabetes mellitus, systolic blood pressure (SBP), diastolic blood pressure (DBP), total cholesterol, triglycerides, high-density lipoprotein cholesterol
(HDLC), low-density lipoprotein cholesterol (LDLC), glucose, C-reaction protein (CRP), interleukin-6 (IL-6), rapid eye movement (REM), sleep efficiency, apneahypopnea index (AHI), oxygen desaturation index (ODI), arterial hemoglobin saturation $\left(\mathrm{SaO}_{2}\right), \mathrm{SaO}_{2}<90 \%$, Epworth sleepiness scale (ESS) and serum or plasma TNFalpha. Information-drawing process was independently implemented by two reviewers (Qingsheng Li and Xin Zheng), who resolved any disagreement by consensus.

Statistical analyses were handled using the STATA software ( $11^{\text {th }}$ version). The changes of circulating TNFalpha were expressed with the weighted mean difference (WMD) along with its $95 \%$ CI. Heterogeneity is measured by the $I^{2}$ statistic, which is calculated as $100 \% \times(\mathrm{Q}-$ d.f. $) / \mathrm{Q}$ (here $\mathrm{Q}$ is the Cochran's heterogeneity statistic and d.f. is the degree of freedom) and describes the percentage of total variation across studies that results from heterogeneity rather than from chance [67]. In case of no heterogeneity (the $I^{2}$ statistic $<50 \%$ ), a fixed-effects model was adopted to calculate the WMD and 95\% CI. Otherwise, a random-effects model was adopted.

Possible causes of heterogeneity were looked for by stratified analyses and meta-regression analyses. Stratified factors included age, gender, country, hypertension, diabetes mellitus, research type, matched condition, diagnostic criteria of controls, diagnostic criteria of OSAS patients and OSAS grade. Other variables modeled in meta-regression analyses included age, gender, BMI, abdomen circumference, neck circumference, smoking, hypertension, diabetes mellitus, SBP, DBP, total cholesterol, triglycerides, HDLC, LDLC, glucose, CRP, IL-6, REM, sleep efficiency, AHI, ODI, $\mathrm{SaO}_{2}, \mathrm{SaO}_{2}<90 \%$ and ESS.

The Begg's funnel plot was created to illustrate the likelihood of publication bias, which was statistically evaluated by the Egger's test. In addition, a filled funnel plot by the fill-and-trim method was also created to determine the number of missing studies with negative findings and filled effect estimates were derived accordingly.

\section{Author contributions}

QL and XZ conceived and carried out the analysis. QL and XZ searched literature and abstract data. XZ performed statistical analyses. QL provided assistance in tables and figures. QL and XZ wrote the manuscript. All authors reviewed the manuscript.

\section{CONFLICTS OF INTERESTS}

There are no competing interests among authors. 


\section{REFERENCES}

1. Tempaku PF, Mazzotti DR, Hirotsu C, Andersen ML, Xavier G, Maurya PK, Rizzo LB, Brietzke E, Belangero SI, Bittencourt L, Tufik S. The effect of the severity of obstructive sleep apnea syndrome on telomere length. Oncotarget. 2016; 7:69216-24. doi: 10.18632/ oncotarget.12293.

2. Peppard PE, Young T, Barnet JH, Palta M, Hagen EW, Hla $\mathrm{KM}$. Increased prevalence of sleep-disordered breathing in adults. Am J Epidemiol. 2013; 177:1006-14.

3. Shamsuzzaman AS, Gersh BJ, Somers VK. Obstructive sleep apnea: implications for cardiac and vascular disease. JAMA. 2003; 290:1906-14.

4. Gonzaga C, Bertolami A, Bertolami M, Amodeo C, Calhoun D. Obstructive sleep apnea, hypertension and cardiovascular diseases. J Hum Hypertens. 2015; 29:70512.

5. Karamanlı H, Özol D, Ugur KS, Yıldırım Z, Armutçu F, Bozkurt B, Yigitoglu R. Influence of CPAP treatment on airway and systemic inflammation in OSAS patients. Sleep Breath. 2014; 18:251-56.

6. McNicholas WT. Obstructive sleep apnea and inflammation. Prog Cardiovasc Dis. 2009; 51:392-99.

7. Goldbart AD, Krishna J, Li RC, Serpero LD, Gozal D. Inflammatory mediators in exhaled breath condensate of children with obstructive sleep apnea syndrome. Chest. 2006; 130:143-48.

8. Sollazzo D, Forte D, Polverelli N, Romano M, Perricone M, Rossi L, Ottaviani E, Luatti S, Martinelli G, Vianelli N, Cavo M, Palandri F, Catani L. Crucial factors of the inflammatory microenvironment (IL-1 $\beta / \mathrm{TNF}-\alpha /$ TIMP-1) promote the maintenance of the malignant hemopoietic clone of myelofibrosis: an in vitro study. Oncotarget. 2016; 7:43974-88. doi: 10.18632/oncotarget.9949.

9. Zhao X, Fan W, Xu Z, Chen H, He Y, Yang G, Yang G, $\mathrm{Hu} \mathrm{H}$, Tang S, Wang P, Zhang Z, Xu P, Yu M. Inhibiting tumor necrosis factor-alpha diminishes desmoplasia and inflammation to overcome chemoresistance in pancreatic ductal adenocarcinoma. Oncotarget. 2016; 7:81110-22. doi: 10.18632/oncotarget.13212.

10. Yan HQ, Zhang D, Shi YY, You X, Shi L, Li Q, Gao FG. Ataxia-telangiectasia mutated activation mediates tumor necrosis factor-alpha induced MMP-13 up-regulation and metastasis in lung cancer cells. Oncotarget. 2016; 7:62070 83. doi: 10.18632/oncotarget.11386.

11. Walsh JA, Duffin KC, Crim J, Clegg DO. Lower frequency of obstructive sleep apnea in spondyloarthritis patients taking TNF-inhibitors. J Clin Sleep Med. 2012; 8:643-48.

12. Ifergane G, Ovanyan A, Toledano R, Goldbart A, AbuSalame I, Tal A, Stavsky M, Novack V. Obstructive Sleep Apnea in Acute Stroke: A Role for Systemic Inflammation. Stroke. 2016; 47:1207-12.

13. Zhang Y, Li NF, Abulikemu S, Zhang DL, Wang YC,
Kong JQ, Nuer GL, Yan ZT, Li HJ, Zhang JH, Zhang XY. Relationship between zinc finger protein 36 (ZFP36) gene polymorphisms and obstructive sleep apnea. Genet Mol Res. 2015; 14:6733-43.

14. Thunström E, Glantz H, Fu M, Yucel-Lindberg T, Petzold M, Lindberg K, Peker Y. Increased inflammatory activity in nonobese patients with coronary artery disease and obstructive sleep apnea. Sleep. 2015; 38:463-71.

15. Leon-Cabrera S, Arana-Lechuga $\mathrm{Y}$, Esqueda-Leon E, Teran-Perez G, Gonzalez-Chavez A, Escobedo G and Velazquez Moctezuma J. Reduced systemic levels of IL-10 are associated with the severity of obstructive sleep apnea and insulin resistance in morbidly obese humans. Mediators Inflamm. 2015; 2015:493409.

16. Kobayashi K, Nishimura Y, Shimada T, Yoshimura S, Funada Y, Satouchi M, Yokoyama M. Effect of continuous positive airway pressure on soluble CD40 ligand in patients with obstructive sleep apnea syndrome. Chest. 2006; 129:632-37.

17. Arias MA, García-Río F, Alonso-Fernández A, Hernanz A, Hidalgo R, Martínez-Mateo V, Bartolomé S, RodríguezPadial L. CPAP decreases plasma levels of soluble tumour necrosis factor-alpha receptor 1 in obstructive sleep apnoea. Eur Respir J. 2008; 32:1009-15.

18. Kanbay A, Kokturk O, Ciftci TU, Tavil Y, Bukan N. Comparison of serum adiponectin and tumor necrosis factor-alpha levels between patients with and without obstructive sleep apnea syndrome. Respiration. 2008; 76:324-30.

19. Nobili V, Cutrera R, Liccardo D, Pavone M, Devito R, Giorgio V, Verrillo E, Baviera G, Musso G. Obstructive sleep apnea syndrome affects liver histology and inflammatory cell activation in pediatric nonalcoholic fatty liver disease, regardless of obesity/insulin resistance. Am J Respir Crit Care Med. 2014; 189:66-76.

20. Li AM, Lam HS, Chan MH, So HK, Ng SK, Chan IH, Lam CW, Wing YK. Inflammatory cytokines and childhood obstructive sleep apnoea. Ann Acad Med Singapore. 2008; 37:649-54.

21. Liu H, Liu J, Xiong S, Shen G, Zhang Z, Xu Y. The change of interleukin- 6 and tumor necrosis factor in patients with obstructive sleep apnea syndrome. J Tongji Med Univ. 2000; 20:200-02.

22. Alberti A, Sarchielli P, Gallinella E, Floridi A, Floridi A, Mazzotta G, Gallai V. Plasma cytokine levels in patients with obstructive sleep apnea syndrome: a preliminary study. J Sleep Res. 2003; 12:305-11.

23. Teramoto S, Yamamoto H, Ouchi Y. Increased C-reactive protein and increased plasma interleukin-6 may synergistically affect the progression of coronary atherosclerosis in obstructive sleep apnea syndrome. Circulation. 2003; 107:E40-40.

24. Ciftci TU, Kokturk O, Bukan N, Bilgihan A. The relationship between serum cytokine levels with obesity 
and obstructive sleep apnea syndrome. Cytokine. 2004; 28:87-91.

25. Imagawa S, Yamaguchi Y, Ogawa K, Obara N, Suzuki N, Yamamoto M, Nagasawa T. Interleukin-6 and tumor necrosis factor-alpha in patients with obstructive sleep apnea-hypopnea syndrome. Respiration. 2004; 71:24-29.

26. Minoguchi K, Tazaki T, Yokoe T, Minoguchi H, Watanabe Y, Yamamoto M, Adachi M. Elevated production of tumor necrosis factor-alpha by monocytes in patients with obstructive sleep apnea syndrome. Chest. 2004; 126:147379.

27. Ryan S, Taylor CT, McNicholas WT. Predictors of elevated nuclear factor-kappaB-dependent genes in obstructive sleep apnea syndrome. Am J Respir Crit Care Med. 2006; 174:824-30.

28. Tam CS, Wong M, McBain R, Bailey S, Waters KA. Inflammatory measures in children with obstructive sleep apnoea. J Paediatr Child Health. 2006; 42:277-82.

29. Bravo ML, Serpero LD, Barceló A, Barbé F, Agustí A, Gozal D. Inflammatory proteins in patients with obstructive sleep apnea with and without daytime sleepiness. Sleep Breath. 2007; 11:177-85.

30. Antonopoulou S, Loukides S, Papatheodorou G, Roussos C, Alchanatis M. Airway inflammation in obstructive sleep apnea: is leptin the missing link? Respir Med. 2008; 102:1399-405.

31. Constantinidis J, Ereliadis S, Angouridakis N, Konstantinidis I, Vital V, Angouridaki C. Cytokine changes after surgical treatment of obstructive sleep apnoea syndrome. Eur Arch Otorhinolaryngol. 2008; 265:1275-79.

32. Li Y, Chongsuvivatwong V, Geater A, Liu A. Are biomarker levels a good follow-up tool for evaluating obstructive sleep apnea syndrome treatments? Respiration. 2008; 76:317-23.

33. Bhushan B, Guleria R, Misra A, Luthra K, Vikram NK. TNF-alpha gene polymorphism and TNF-alpha levels in obese Asian Indians with obstructive sleep apnea. Respir Med. 2009; 103:386-92.

34. Carneiro G, Togeiro SM, Ribeiro-Filho FF, Truksinas E, Ribeiro AB, Zanella MT, Tufik S. Continuous positive airway pressure therapy improves hypoadiponectinemia in severe obese men with obstructive sleep apnea without changes in insulin resistance. Metab Syndr Relat Disord. 2009; 7:537-42.

35. Li Y, Chongsuvivatwong V, Geater A, Liu A. Exhaled breath condensate cytokine level as a diagnostic tool for obstructive sleep apnea syndrome. Sleep Med. 2009; 10:95103.

36. Tamaki S, Yamauchi M, Fukuoka A, Makinodan K, Koyama N, Tomoda K, Yoshikawa M, Kimura H. Production of inflammatory mediators by monocytes in patients with obstructive sleep apnea syndrome. Intern Med. 2009; 48:1255-62.

37. Thomopoulos C, Tsioufis C, Dimitriadis K, Tsiachris
D, Tousoulis D, Manolis A, Alchanatis M, Kallikazaros I, Stefanadis C. Obstructive sleep apnoea syndrome is associated with enhanced sub-clinical inflammation and asymmetric dimethyl-arginine levels in hypertensives. $\mathrm{J}$ Hum Hypertens. 2009; 23:65-67.

38. Kim J, Lee CH, Park CS, Kim BG, Kim SW, Cho JH. Plasma levels of MCP-1 and adiponectin in obstructive sleep apnea syndrome. Arch Otolaryngol Head Neck Surg. 2010; 136:896-99.

39. Li NF, Yao XG, Zhu J, Yang J, Liu KJ, Wang YC, Wang $\mathrm{XL}, \mathrm{Zu}$ FY. Higher levels of plasma TNF-alpha and neuropeptide $\mathrm{Y}$ in hypertensive patients with obstructive sleep apnea syndrome. Clin Exp Hypertens. 2010; 32:5460.

40. Sahlman J, Miettinen K, Peuhkurinen K, Seppä J, Peltonen M, Herder C, Punnonen K, Vanninen E, Gylling H, Partinen M, Uusitupa M, Tuomilehto H, and Kuopio Sleep Apnoea Group. The activation of the inflammatory cytokines in overweight patients with mild obstructive sleep apnoea. J Sleep Res. 2010; 19:341-48.

41. Steiropoulos P, Papanas N, Nena E, Antoniadou M, Serasli E, Papoti S, Hatzizisi O, Kyriazis G, Tzouvelekis A, Maltezos E, Tsara V and Bouros D. Inflammatory markers in middle-aged obese subjects: does obstructive sleep apnea syndrome play a role? Mediators Inflamm. 2010; 2010:675320.

42. Khalyfa A, Serpero LD, Kheirandish-Gozal L, Capdevila OS, Gozal D. TNF- $\alpha$ gene polymorphisms and excessive daytime sleepiness in pediatric obstructive sleep apnea. J Pediatr. 2011; 158:77-82.

43. Deboer MD, Mendoza JP, Liu L, Ford G, Yu PL, Gaston BM. Increased systemic inflammation overnight correlates with insulin resistance among children evaluated for obstructive sleep apnea. Sleep Breath. 2012; 16:349-54.

44. Medeiros CA, de Bruin VM, Andrade GM, Coutinho WM, de Castro-Silva C, de Bruin PF. Obstructive sleep apnea and biomarkers of inflammation in ischemic stroke. Acta Neurol Scand. 2012; 126:17-22.

45. Qian X, Yin T, Li T, Kang C, Guo R, Sun B, Liu C. High levels of inflammation and insulin resistance in obstructive sleep apnea patients with hypertension. Inflammation. 2012; 35:1507-11.

46. Alexopoulos EI, Theologi V, Malakasioti G, Maragozidis P, Tsilioni I, Chrousos G, Gourgoulianis K, Kaditis AG. Obstructive sleep apnea, excessive daytime sleepiness, and morning plasma TNF- $\alpha$ levels in Greek children. Sleep. 2013; 36:1633-38.

47. Chen PC, Guo CH, Tseng CJ, Wang KC, Liu PJ. Blood trace minerals concentrations and oxidative stress in patients with obstructive sleep apnea. J Nutr Health Aging. 2013; 17:639-44.

48. Doufas AG, Tian L, Padrez KA, Suwanprathes P, Cardell JA, Maecker HT, Panousis P. Experimental pain and opioid analgesia in volunteers at high risk for obstructive sleep 
apnea. PLoS One. 2013; 8:e54807.

49. Driessen C, Plomp RG, van der Spek PJ, Ince C, Kulik W, Mathijssen IM, Joosten KF. Is there an effect of obstructive sleep apnea syndrome on oxidative stress and inflammatory parameters in patients with craniofacial anomalies? J Craniofac Surg. 2013; 24:1908-13.

50. Hargens TA, Guill SG, Kaleth AS, Nickols-Richardson SM, Miller LE, Zedalis D, Gregg JM, Gwazdauskas F, Herbert WG. Insulin resistance and adipose-derived hormones in young men with untreated obstructive sleep apnea. Sleep Breath. 2013; 17:403-09.

51. Yang D, Liu Z, Luo Q. Plasma ghrelin and proinflammatory markers in patients with obstructive sleep apnea and stable coronary heart disease. Med Sci Monit. 2013; 19:251-56.

52. Ciccone MM, Scicchitano P, Zito A, Cortese F, Boninfante B, Falcone VA, Quaranta VN, Ventura VA, Zucano A, Di Serio F, Damiani MF, Resta O. Correlation between inflammatory markers of atherosclerosis and carotid intimamedia thickness in Obstructive Sleep Apnea. Molecules. 2014; 19:1651-62.

53. Yadav R, France M, Aghamohammadzadeh R, Liu Y, Hama S, Kwok S, Schofield J, Turkington P, Syed AA, Malik R, Pemberton P, Greenstein A, Durrington P, et al. Impairment of high-density lipoprotein resistance to lipid peroxidation and adipose tissue inflammation in obesity complicated by obstructive sleep apnea. J Clin Endocrinol Metab. 2014; 99:3390-98.

54. De Santis S, Cambi J, Tatti P, Bellussi L, Passali D. Changes in ghrelin, leptin and pro-inflammatory cytokines after therapy in Obstructive Sleep Apnea Syndrome (OSAS) patients. Otolaryngol Pol. 2015; 69:1-8.

55. Jiang H, Cao H, Wang P, Liu W, Cao F, Chen J. Tumour necrosis factor- $\alpha /$ interleukin-10 ratio in patients with obstructive sleep apnoea hypopnoea syndrome. J Laryngol Otol. 2015; 129:73-78.

56. Lin CC, Liaw SF, Chiu CH, Chen WJ, Lin MW, Chang FT. Effects of nasal CPAP on exhaled SIRT1 and tumor necrosis factor- $\alpha$ in patients with obstructive sleep apnea. Respir Physiol Neurobiol. 2016; 228:39-46.

57. Fornadi K, Lindner A, Czira ME, Szentkiralyi A, Lazar AS, Zoller R, Turanyi CZ, Veber O, Novak M, Mucsi I, Molnar MZ. Lack of association between objectively assessed sleep disorders and inflammatory markers among kidney transplant recipients. Int Urol Nephrol. 2012; 44:607-17.
58. Vgontzas AN, Papanicolaou DA, Bixler EO, Kales A, Tyson K, Chrousos GP. Elevation of plasma cytokines in disorders of excessive daytime sleepiness: role of sleep disturbance and obesity. J Clin Endocrinol Metab. 1997; 82:1313-16.

59. Esposito E, Cuzzocrea S. TNF-alpha as a therapeutic target in inflammatory diseases, ischemia-reperfusion injury and trauma. Curr Med Chem. 2009; 16:3152-67.

60. Sfikakis PP. The first decade of biologic TNF antagonists in clinical practice: lessons learned, unresolved issues and future directions. Curr Dir Autoimmun. 2010; 11:180-210.

61. Kaushal N, Ramesh V, Gozal D. TNF- $\alpha$ and temporal changes in sleep architecture in mice exposed to sleep fragmentation. PLoS One. 2012; 7:e45610.

62. Ding X, Yu C, Liu Y, Yan S, Li W, Wang D, Sun L, Han Y, Li M, Zhang S, Yun F, Zhao H, Li Y. Chronic obstructive sleep apnea accelerates pulmonary remodeling via TGF- $\beta /$ miR-185/CoLA1 signaling in a canine model. Oncotarget. 2016; 7:57545-55. doi: 10.18632/oncotarget.11296.

63. Loubaki L, Jacques E, Semlali A, Biardel S, Chakir J, Sériès F. Tumor necrosis factor-alpha expression in uvular tissues differs between snorers and apneic patients. Chest. 2008; 134:911-18.

64. Nadeem R, Molnar J, Madbouly EM, Nida M, Aggarwal S, Sajid H, Naseem J, Loomba R. Serum inflammatory markers in obstructive sleep apnea: a meta-analysis. J Clin Sleep Med. 2013; 9:1003-12.

65. Engels EA, Schmid CH, Terrin N, Olkin I, Lau J. Heterogeneity and statistical significance in meta-analysis: an empirical study of 125 meta-analyses. Stat Med. 2000; 19:1707-28.

66. Stroup DF, Berlin JA, Morton SC, Olkin I, Williamson GD, Rennie D, Moher D, Becker BJ, Sipe TA, Thacker SB. Meta-analysis of observational studies in epidemiology: a proposal for reporting. Meta-analysis Of Observational Studies in Epidemiology (MOOSE) group. JAMA. 2000; 283:2008-12.

67. Higgins JP, Thompson SG, Deeks JJ, Altman DG. Measuring inconsistency in meta-analyses. BMJ. 2003; 327:557-60. 